\title{
A pack a day: Just what the doctor ordered?
}

$\mathrm{S}$ mokers in Iceland may soon need a doctor's note to light up. Member of Parliament and former health minister Siv Fridleifsdottir, backed by the country's medical association, will table a private member's bill in the fall to make cigarettes a prescription-only product. Only pharmacies would be allowed to dispense tobacco products - at first to anyone over 20 and finally only to people with medical certificates.

The pitch is part of an ambitious 10year plan articulated in the bill to ban smoking in all public places, including sidewalks, parks and cars when driving or with children, in a bid to reduce the visibility and harmful second-hand effects of smoking. Under the legislation, doctors would be compelled to prescribe cigarettes to smokers unwilling or unable to quit using cessation programs.

"The idea is not to penalize those who already smoke, but prevent others, particularly young people, from making uninformed choices to pick up the habit," explains Fridleifsdottir.

Iceland has one of the lowest rates of smoking in Europe at about $15 \%$, largely because of antismoking policies adopted in the past, but the rate is higher among young Icelanders at 20\%.

"Every year 700 young people start smoking in Iceland, and about half will die prematurely from diseases related to that addiction," Fridleifsdottir says. "With all that we know today about how harmful it is to smoke, it is ethical and right to take radical steps to try and prevent children from starting to smoke."

The proposed legislation would see tobacco and nicotine designated as addictive drugs, while second-hand smoke would be controlled like other carcinogenic substances.

The price of tobacco products would increase by $10 \%$ annually so long as they're available over the counter - a strategy that's been proven to reduce smoking rates by as much as $6 \%$ else-

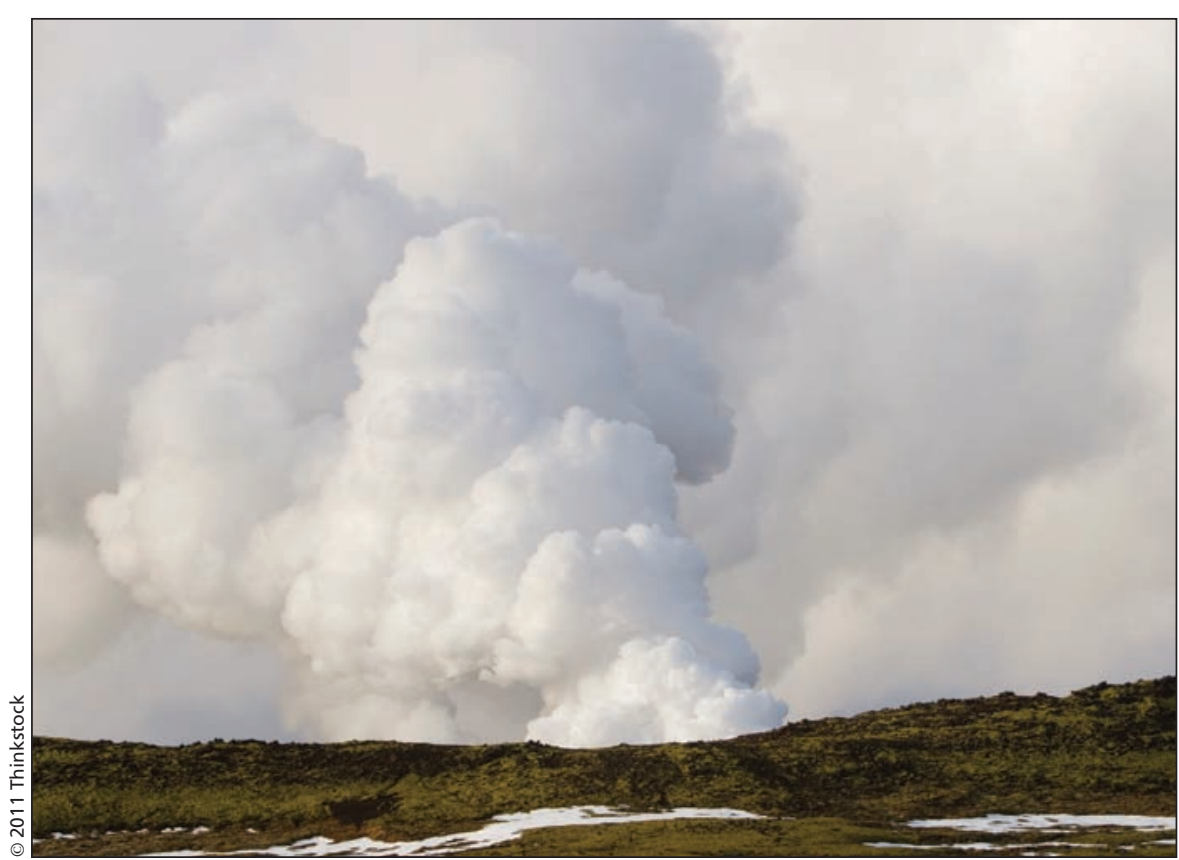

Iceland may soon confine smoking to people's residences as part of a 10-year plan that would ban smoking in all public places, including sidewalks, parks and cars when driving or with children, in a bid to reduce the visibility and harmful second-hand effects of smoking.

where. But once the prescription system was in place, prices would be cut to the cost of importing the products, as it would be unfair to tax people unable to quit, Fridleifsdottir says. "We'd classify smokers as being addicted to tobacco, and look at tobacco as medicine for that addiction."

The prescription system would also serve as an entry point for smokers to receive regular medical care to mitigate and manage the long-term health effects of their habit.

But few smokers are eager to be diagnosed as addicts and public debate surrounding the proposal has already resurrected some "old ghost" controversies, Fridleifsdottir says. "All the arguments we heard in 2006 and 2007 when we banned smoking in restaurants, bars and discotheques have come back around. They say now, like then, that the proposal is too radical, that it goes too far against personal freedoms. I've even heard some really old-fashioned arguments that second- hand smoke is not harmful, arguments I thought we had put behind us for many years."

But as with prior antismoking initiatives, what's considered radical is only a matter of time and perspective, she counters. "Today we wouldn't think of lighting up on a plane, and yet it once was radical to propose such a ban. Even our most recent ban in 2007 stirred all kinds of debate, but we've since done opinion polls and it's overwhelmingly supported. It's just a matter of time for the steps we're suggesting to become a reality."

But strong antismoking measures and sales bans are only effective if enforced, says Armando Peruga, program manager of the World Health Organization's Tobacco Free Initiative. "That includes ensuring no alternative markets are created by the measure."

The success of Iceland's proposed prescription system is anyone's guess, he adds. Only Bhutan has ever imposed a total ban on tobacco products, and 
treating cigarettes as prescription drugs is an entirely novel approach.

Yet Iceland, by virtue of its isolated geography, may be in the perfect position to impose such strictures as there are few points of access by air or sea for tobacco products to be smuggled into the country, Peruga says.

Moreover, imported tobacco sold at premium prices on the black market could hardly compete if the physicianprescribed stuff was sold wholesale, says Fridleifsdottir.

If anything, the ethical implications of involving physicians in dispensing tobacco is a greater concern, argues Peruga. "If it goes ahead, there should be firm guidelines to define the indica- tions for such a prescription, based on consensus between Iceland's medical association and the government."

In response to criticisms of the initiative, Fridleifsdottir plans to make some modifications to the private member's bill before tabling it in Parliament in October. "We were going to propose the public smoking ban be extended to balconies, but we see the argument that if you're a smoker with children and don't want to smoke inside there's really nowhere else to go without leaving home," she explains. "We were also suggesting that taxpayers' money not be used to pay [subsidies] for films produced in Iceland if they show people smoking, but artists criticized us for destroying their freedom of expression so perhaps we'll agree to support those films if the artists can prove the tobacco industry is not sponsoring them."

Even if Parliament were to neuter the proposal, as some have suggested, by making tobacco products only available from licensed stores, as alcohol now is, it would be incremental progress, Fridleifsdottir adds. "The value of linking it to a prescription system would be lost, but any step to reduce the availability and visibility of tobacco is one in the right direction." — Lauren Vogel, CMAJ

CMAJ 2011. DOI:10.1503/cmaj.109-3969 